\title{
SUPORTE FAMILIAR DE NONAGENÁRIOS E CENTENÁRIOS DURANTE A
} ATUAL PANDEMIA DE COVID-19

Aline Mendes da Rosa; PUCRS; alinemdrosa@hotmail.com Julia de Freitas Machado; PUCRS; juliadfmachado@hotmail.com

Ângelo José Gonçalves Bós; PUCRS; angelo.bos@pucrs.br

- Escola de Medicina da PUCRS, Porto Alegre, Brasil; - Projeto de extensão Atenção Multiprofissional ao Longevo (AMPAL) da PUCRS, Porto Alegre, Brasil

\section{RESUMO}

Introdução: Nonagenários e centenários apresentam elevadas taxas comorbidades fazendo com que eles necessitem de um suporte social. Geralmente esse suporte é familiar e que pode estar comprometido durante a COVID-19. Objetivo: Estudar a funcionalidade familiar durante o isolamento social devido a atual pandemia de COVID-19. Método: É um estudo transversal e analítico com nonagenários e centenários do projeto Atenção Multiprofissional ao Longevo (AMPAL) acompanhados desde 2016. O suporte familiar foi medido pelo "APGAR de família" que permite a avaliação subjetiva da funcionalidade familiar. O APGAR é composto por cinco itens: ajuda recebida, compartilham problemas, apoio recebido, afeição recebida e tempo compartilhado. Os dados foram coletados via contato telefônico entre os meses de maio a julho de 2020 e comparados com dados anteriores dos mesmos longevos. Foram analisadas as possíveis mudanças em cada item do APGAR e a sua associação com gênero, faixa etária e se mora sozinho antes e durante os primeiros meses da COVID19. Resultados: Foram entrevistados 55 nonagenários e centenários, a maioria mulheres (74\%) e residindo com familiar/cuidador (80\%). A ajuda que recebe diminuiu em $4 \%$ e aumentou em $16 \%$ aumento. Houve diminuição de $2 \%$ no compartilhamento de problemas, apoio recebido e afeição recebida. Entretanto, os participantes relataram uma diminuição de $40 \%$ do tempo com a família. Conclusão: Os nonagenários e centenários apresentaram bom apoio familiar, mas referiram diminuição do tempo que passam com os familiares, mesmo morando com a família. Essa diminuição do contato com familiares pode resultar em aumento de sintomas depressivos e de ansiedade.

Palavras-chaves: Nonagenários e centenários, isolamento social, suporte social Covid19.

Agradecimentos: "Este estudo foi parcialmente financiado pela Coordenação de Aperfeiçoamento de Pessoal de Nível Superior - Brasil (CAPES) - Código Financeiro 001”. 